\title{
Testing the potential of Multiobjective Evolutionary Algorithms (MOEAs) with Colorado water managers
}

\section{Rebecca Smitha, Joseph Kasprzyk ${ }^{b}$, Lisa Dilling ${ }^{c, d}$}

aBureau of Reclamation, 1777 Exposition Dr Ste 113, Boulder, Colorado, 80301

${ }^{b}$ Department of Civil, Environmental, and Architectural Engineering, University of Colorado, 607 UCB, Boulder, Colorado, 80309, USA

'Environmental Studies Program, University of Colorado, 397 UCB, Boulder, Colorado 80309, USA,

${ }^{d}$ Western Water Assessment, University of Colorado, CIRES, 216 UCB, Boulder, Colorado, 80309, USA

Rebecca Smith: resm1653@colorado.edu (corresponding author)

Joseph Kasprzyk: Joseph.Kasprzyk@colorado.edu

Lisa Dilling: Idilling@colorado.edu

\section{Highlights}

- Structured workshop effectively provided managers with hands-on tradeoff experience

- Interactive MOEA tradeoffs aided in creation of decision dominance structure 
- Increasing tradeoff info often resulted in revised and divergent portfolio choices

- Managers suggested opportunities and challenges to using MOEAs for planning

\section{Abstract}

Multiobjective Evolutionary Algorithms (MOEAs) generate quantitative information about performance relationships between a system's potentially conflicting objectives (termed tradeoffs). Research applications have suggested that evaluating tradeoffs can enhance long term water utility planning, but no studies have formally engaged with practitioners to assess their perceptions of tradeoffs generated by MOEAs. This article examines how practitioners interact with MOEA tradeoffs and reports their ideas for how their agencies could use MOEA results. We hosted a group of Colorado water managers at a charrette, or structured investigatory workshop, where they directly interacted with tradeoffs, discussed how they used the information, and linked their workshop experiences to opportunities for MOEAs to enhance their agencies' planning processes. Among other interesting results, we found that managers' portfolio preferences diverged as tradeoff information increased and that structured information about the relationships between decision levers and performance would be beneficial for interpreting tradeoffs.

\section{Keywords}

participatory modeling; workshop; multiobjective evolutionary algorithm (MOEA); decision-making; long term planning; tradeoffs

\section{Introduction}

Decision making is a process; when a choice is available to be made, deliberation must occur if an agent desires an outcome and is able to take action (Aristotle, 1920). In most decision making processes, preferences are constructed based on problem framing, previous experience, and available information, time, and resources (Payne et al., 1992; Roy, 1999; Slovic, 1995; Tsoukias, 2008). In combination, these factors help decision makers develop what Montgomery (1983) terms a "dominance structure". A dominance structure is a set of cognitive rules that serve to create advantages for certain alternatives or neutralize disadvantages of others. Such a framework is necessary when there is no strictly-optimal option. The dominance structure is iteratively built up in stages using mechanisms that help decision makers assess relative merits of alternatives and/or alter their internal representations of situations until one alternative becomes dominant. This process of creating arguments for and against alternatives develops a justification, or basis for reasoning that can be conveyed to others. Justifiability is a 
cornerstone of deliberate human decision making (Connolly and Reb, 2012; Payne et al., 1992; Slovic, 1975; Tversky, 1972), and studying this in technology-based decision support is warranted.

Multiobjective Evolutionary Algorithms (MOEAs) have been researched and applied as tools to aid decision making processes concerning complex systems for which there are multiple conflicting performance measures. MOEAs seek to optimize system performance in multiple performance objectives, efficiently searching through thousands of alternatives to develop a set that quantitatively characterizes the approximate best tradeoffs between those objectives. These quantified tradeoffs reveal how much performance in one objective must be forfeited to get better performance in another. In the context of developing a long term water resources plan, MOEAs test thousands of alternative portfolios of new sources, new infrastructure, and new operations in order to balance between performance objectives such as maximizing supply reliability and minimizing environmental impact.

Several studies have applied MOEAs to long term water resources planning problems. Long term plans are essentially overarching decisions about pursuing a set of actions over an extended time horizon. Three recent academic examples are Matrosov et al.'s use of an MOEA to develop long term planning portfolios for London, balancing cost, energy use, resilience and environmental objectives (2015); Zeff et al (2016) optimization of long and short term risk triggers to develop adaptation strategies and support regional cooperation between utilities in North Carolina; and Wu et al.'s application of multiobjective optimization to identify portfolios of traditional and alternative water sources for Adelaide in consideration of cost, emissions, reliability, and the environmental impacts of water and wastewater reuse (2017). These studies demonstrate that MOEAs can produce informative tradeoffs for multiple aspects of planning in a variety of geographic contexts which could inform agencies' planning decisions. However, none of these examples have undertaken a structured exploration of how a practitioner or agency employing an MOEA would interact with or perceive tradeoffs, and thus have not determined whether or how they actually aid decision making.

To study whether the quantitative information found in MOEA tradeoffs contributes to the creation of defensible dominance structures that help water managers construct preferences and justify decisions, researchers need to be able to observe, interrogate, and analyze practitioners' usage of tradeoffs. Accomplishing this necessitates an interface between practitioners and researchers designed specifically around the type of information that results from MOEA-assisted optimization. Here, we can draw on an approach called a "charrette" which is used in non-academic settings to achieve a high level of public awareness and input on the design or vision of a community project or plan (US EPA, 2014). Charrettes 
are also used by researchers in the fields of construction management and safety. Research charrettes are structured workshops that bring together industry professionals and academics in a relatively short but intensely productive session in order to generate discussion and feedback about newly-created products or practices intended for industry use (Gibson and Whittington, 2010). Charrettes combine the advantages of surveys, interviews, and focus groups in an accelerated time frame, overcoming the difficulties of undertaking these methods individually (e.g. low response rates, time commitments from both researchers and practitioners, access to data, etc.). Results from applying these mixed methods to technical research topics have shown that charrettes can offer both short and long term benefits to participating industry professionals and improved validity and reliability of research outcomes (Abowitz and Toole, 2010; Green et al., 2010).

This paper presents the content, methods, and results of a research charrette through which our transdisciplinary research team engaged with Front Range, Colorado, water managers over the use of MOEA tradeoff information for long term water utility planning. The workshop was designed to discover how practitioners used tradeoff information to make decisions, and whether and how the managers perceived the information to be useful in their agencies' planning processes. The goals of the workshop were to expose practitioners to an emerging tool and use the collected data to hone future MOEA research agendas and target new applications.

The charrette that we focus on in this paper is the culmination of a larger study that introduced and applied the Participatory Framework for Assessment and Improvement of Tools (ParFAIT) (Smith et al., 2017). The following section briefly introduces MOEAs and presents work from the previous phases of our ParFAIT efforts that pertain to this final step in the framework. In Section 3, we describe the methods and content from our workshop. Next, we describe the results, and in Section 5 offer concluding remarks.

\section{Background}

\subsection{MOEA-assisted optimization for long term water utility planning}

For water utilities, planning for long term, sustainable water security is a critical task and a major undertaking. Technical staff review alternative planning portfolios and iteratively discuss goals, needs, and strategies with Board- or council-level decision makers (CSU, 2017a; MWD, 2015), and, increasingly, the public as well (WUCA, 2015). They generally do not find a perfect plan due to the conflicts between 
the financial, social, and environmental factors that utilities must navigate (Elkington, 2004), but utilities strive to make smart, responsible, and justifiable decisions that allow their systems to meet the communities' chosen demand reliability policies in combination with community values.

Multiobjective Evolutionary Algorithm (MOEA)-assisted optimization has been studied (Matrosov et al., 2015; Mortazavi et al., 2012; Smith et al., 2018; Wu et al., 2016) and applied (Basdekas, 2014; CSU, 2017a) as a method to help utilities develop long term plans. While a traditional planning process compares the performance of a handful of planning portfolios, MOEA-assisted optimization efficiently designs and tests thousands of potential portfolios. This extensive search and evaluation produces quantitative information about the system's performance in multiple objectives and the tradeoff relationships between those objectives.

Performing MOEA-assisted optimization requires a simulation model (already developed by most utilities), a problem formulation, an MOEA, and tradeoff visualizations. The problem formulation is a set of decision levers, objectives, and constraints that the MOEA uses to construct and compare planning portfolios. Decision levers are a utility's options to modify its system, e.g. building a reservoir or enacting conservation; the set of chosen decision levers makes up a portfolio. Objectives are measures of system performance that are quantified representations of a system's goals or purposes, e.g. minimizing frequency of lawn watering restrictions or maximizing water in storage. Constraints are numeric limits to acceptable performance, e.g. if a portfolio cannot meet $100 \%$ of indoor demand at all times it is not considered a valid planning approach.

MOEA-assisted optimization is carried out through many cycles of a computational loop. The MOEA generates an initial population of portfolios and feeds each one to the simulation model, which tests the portfolio over one or more future scenarios. At the end of the simulation, values for objectives and constraints are reported back to the MOEA. This loop iterates thousands of times, during which the MOEA intelligently evolves new "generations" of portfolios through both systematic and random recombination and mutation of the high-performing portfolios of previous generations. This results in a set of nondominated portfolios in which performance improvement in one objective is only achieved by sacrificing performance in another; thus, the portfolios "trade off" levels of performance. Analyzing the tradeoffs requires careful analysis including visualization techniques, and these are the final component of MOEA-assisted optimization. More information about tradeoff visualization is presented in Section 3.1. 
Water utility planning is a complex process which may benefit from new technologies. Increased public scrutiny, greater mandates to protect social and environmental interests, and heightened awareness of future uncertainty all suggest that extensive portfolio search and explicit performance tradeoff information would be useful to the agencies.

\subsection{Participatory Framework for Assessment and Improvement of Tools (ParFAIT)}

Many research applications of MOEA-assisted optimization have established the ability of MOEAs to generate tradeoff information about water supply systems and produce innovative portfolios that can outperform plans developed with human expertise or previously-established operational approaches (Maier et al., 2014; Nicklow et al., 2010). While Colorado Springs Utilities and Melbourne Water are two notable examples (CSU, 2017b; Kularathna et al., 2015), instances of this promising tool being applied in real-world planning studies are rare. To understand and potentially overcome the limited uptake of MOEA-assisted optimization, researchers must consider the factors that lead industries to adopt tools and consciously seek to create usable science. That is, researchers must undertake intentional, iterative interaction with practitioners to understand their needs, transmit research, and co-produce relevant future research directions (Díez and McIntosh, 2009; Dilling and Lemos, 2011; Sarewitz and Pielke, 2007; Smits, 2002).

The Participatory Framework for Assessment and Improvement of Tools (ParFAIT) is a research process designed to bring academics and practitioners together in a structured way (Smith et al., 2017). ParFAIT is a four-phase research sequence that can be summarized as follows:

Step 1: Choose a promising research tool and a practical use for it that is supported by academic literature and knowledge of the proposed industry;

Step 2: Hold Workshop 1 to solicit input from practitioners that will inform development of a tool testbed. (A testbed is a platform on which the tool can be demonstrated to practitioners.);

Step 3: Build the tool testbed, iterating with practitioners as necessary to ensure relatability and relevance to real-world tool application context;

Step 4: Hold Workshop 2, a research charrette, to solicit practitioner feedback on the testbed results (i.e. results representative of what they could expect if their agencies adopted the tool). 
Smith et al. (2017) introduced ParFAIT, including the detailed steps and methodology, the supporting theory behind the process, and the results of Workshop 1 (briefly summarized below). The ParFAIT purpose and process distinguish the study presented in this paper from previous MOEA research studies which either applied the tool to a stylized system without input from practitioners or worked with water managers to inform its application to a real system. This study instead seeks to create a context and platform through which practitioners from many agencies can gain experience using MOEA tradeoffs and provide their feedback to researchers. Here, we present results from our application of ParFAIT, including a charrette with utility managers to understand their engagement with tradeoffs and the overall usability of MOEAs for long-term decision making.

\subsubsection{ParFAIT Workshop 1}

Workshop 1 of our ParFAIT process took place in February, 2015. It brought together water managers from six Front Range, Colorado, utilities ${ }^{1}$ and our research team which was made up of engineering, social science, and climate science researchers as well as water utility practitioners. Through targeted but free-form group discussions, managers shared their experiences of Front Range management challenges and provided feedback and suggestions to inform the elements needed to create an MOEAassisted optimization testbed: supply and demand decision levers, performance objectives and constraints, future supply and demand scenarios, and important features for a generic but relevant hypothetical water supply simulation model.

Creating a relatable testbed is crucial for the successful application of ParFAIT because it is the basis for generating representative results, and also because its components must be recognizable to participants in the second ParFAIT workshop. This enables them to quickly grasp the testbed and focus on engaging with the results. Based on the information we generated through Workshop 1 and iteration with practitioners on our research team, we developed the problem formulation (decision levers, objectives, and constraints) and water supply simulation model that make up the Eldorado Utility Planning Model testbed.

\subsubsection{ParFAlT testbed: The Eldorado Utility Planning Model and case study}

To demonstrate MOEA-assisted optimization, we used the context of a hypothetical water utility, called "Eldorado Utility," undertaking a long term planning process. The Eldorado Utility Planning Model and

\footnotetext{
${ }^{1}$ City of Aurora, City of Boulder, Colorado Springs Utilities, Denver Water, City of Fort Collins, and Northern Water
} 
case study generically capture management context relevant to utilities on the Front Range of Colorado as well as other regions in the western U.S. The rest of this section will briefly describe Eldorado Utility's supply system and problem formulation, the model, and minimal pertinent Front Range context. Technical details about the optimization problem are included in the Appendix. For more Front Range context, refer to Smith et al. (2017), and for in depth discussion about the model and case study results, refer to Smith et al (2018).

Much of the western U.S. is severely water-limited and tightly regulated by the prior appropriation legal doctrine, or "first in time, first in right" (Hobbs, 2004). One practical outcome of these factors is that, as cities grow, they obtain a variety of types of water rights (e.g. storage rights and streamflow diversion rights), each with different temporal priorities, and which may be sourced from multiple geographic locations. To represent this, Eldorado's hypothetical system includes: two reservoirs on two different rivers with junior priority dates; three direct diversion streamflow rights on a nearby river - one senior, one mid-seniority, and one junior; one junior diversion right on a distant river that requires the diverted water to be conveyed under a mountain range in order to be stored closer to the utility; and 10,000 shares of a water wholesale company that Eldorado takes directly from a reservoir owned and operated by the wholesaler.

In many years, junior right holders do not all get their full allotments (Caulfield Jr. et al., 1987; P. O. Abbott, 1985); e.g., a reservoir does not necessarily fill or a streamflow right does not always get to divert. Streamflow and competition for water on different rivers varies, however, and this means that utilities' water supplies strategically span entire regions. The Eldorado Utility Planning Model encompasses 5 basins and 12 water users besides Eldorado. The other users with senior water rights often limit the yields from most of Eldorado's sources, but some also provide opportunities for the utility to acquire more reliable supplies.

The Eldorado Utility is a relatively small water provider and, like much of the western U.S., is expecting rapid population growth (State of Colorado, 2017). The utility has a set of 13 decision levers it can use to modify its system to meet growing demands. The levers fall into three general categories: pursuing "new" water, building new storage, and altering management of reusable water. The first category includes decisions about leasing strategic space in other agencies' reservoirs and obtaining the right to move reusable water around the region for more efficient access. Pursuing "new" water refers to decisions to acquire rights from regional agricultural or industrial users, or buying shares from water 
wholesalers. Conservation is also considered new water because it frees up water that would have otherwise not been available to meet growing demands. Building new storage includes decisions about whether and how much to expand an existing reservoir and whether to build a new one either upstream, downstream, or both.

Eldorado has defined five ${ }^{2}$ performance objectives on which to evaluate potential portfolios. They are qualitatively described here and also summarized in Table 1. The first objective, "Years in Restriction 1" seeks to minimize how frequently Eldorado goes into Level 1 restrictions, which occurs when the utility's storage drops below $75 \%$ of average annual demand ${ }^{3}$. Eldorado's reliability policy dictates that the utility should not enact these restrictions more than 5 times in 25 years. The next objective captures the utility's desire to minimize missed opportunities, i.e. inability to use available water (“Missed Op Water"); this measures how much of certain types of water that Eldorado had access to but could not use due to incompatible demand timing, lack of storage, etc. Next, Eldorado seeks to minimize "New Supply"; this means minimizing the average annual volume of water over the course of the simulation that Eldorado acquires through decisions such as buying rights or shares or conserving water (i.e. freeing up water to meet new demands). While Eldorado does need more water for a growing population, this objective is minimized because drawing more water than necessary away from other users creates social and economic disruption in their communities. The "New Storage" objective minimizes the volume of newly-built storage within a portfolio because adding infrastructure is expensive, uncertain, and environmentally problematic. Finally, measuring "April 1 Storage-to-Demand" is another way for Eldorado to evaluate the reliability of their system; this objective seeks to maximize the lowest April $1^{\text {st }}$ storage volume over the course of the simulation (i.e. it measures how much water is left in storage at the end of the winter drawdown season).

The single constraint included in the problem formulation was that all portfolios had to meet $100 \%$ of indoor demand (demand remaining after outdoor water use is prohibited by Level 3 restrictions).

\footnotetext{
2 The full optimization problem had two additional restrictions-based objectives that were not presented in the workshop but which are described in the Appendix.

${ }^{3}$ When storage drops below $50 \%$ of annual demand, more severe restrictions are triggered but those were not presented in the workshop (see the previous footnote).
} 
Table 1. Summary of performance objectives.

\begin{tabular}{|c|c|}
\hline Objective & Description \\
\hline $\begin{array}{l}\text { Years in } \\
\text { Restriction } 1\end{array}$ & Minimize frequency of Level 1 restrictions over 25 years \\
\hline Missed Op & $\begin{array}{l}\text { Minimize average annual volume of the sum of: return flows that Eldorado could } \\
\text { have captured and reused, forfeited Wholesaler shares, and forfeited Ag2 shares }\end{array}$ \\
\hline New Supply & $\begin{array}{l}\text { Minimize average annual new water created by either conserving or acquiring right } \\
\text { and shares }\end{array}$ \\
\hline New Storage & Minimize the volume of newly-built storage in a portfolio \\
\hline $\begin{array}{l}\text { April } 1 \text { Storage- } \\
\text { to-Demand }\end{array}$ & $\begin{array}{l}\text { Maximize the lowest April } 1^{\text {st }} \text { storage-to-annual demand ratio during the } 25 \text {-year } \\
\text { simulation }\end{array}$ \\
\hline
\end{tabular}

The Eldorado Utility and regional system are modeled using the RiverWare platform (Zagona et al., 2001). The optimization was performed on a 25 -year simulation horizon with a monthly timestep using the Borg MOEA (Hadka and Reed, 2013). Optimizations were performed in three different hydrologic scenarios: historic, streamflow resulting from a $1^{\circ} \mathrm{C}$-perturbed future (qualitatively named "Very Warm" for workshop purposes), and streamflow resulting from a $4^{\circ} \mathrm{C}$-perturbed future (referred to as "Very Hot" in the workshop). These temperatures were based on a previous climate change study in which all of our Front Range utilities participated; more information about the choice of these scenarios can be found in Woodbury et al (2012) and a description of their generation is in Smith et al (2018).

\section{Methods}

\subsection{Interactive tradeoff visualization workbooks}

To explore and understand the quantitative tradeoffs contained within a set of nondominated portfolios produced by MOEA-assisted optimization, users need to be able to see the complex relationships between the portfolios. This is facilitated by visualizing multiple portfolios at a time in several objectives, or dimensions. Being able to see relationships across all dimensions simultaneously provides the greatest opportunity to see tradeoffs, since only seeing a subset of the objectives can obscure higherdimensional relationships (Kollat and Reed, 2007). Understanding and exploring a large dataset in many dimensions requires advanced visualization techniques called visual analytics (Keim et al., 2006; Liu et al., 2017; Thomas and Cook, 2006; Woodruff et al., 2013). 
This study uses parallel axis plotting. The plots use a series of vertical axes to represent as many dimensions as desired (Fleming et al., 2005; Herman et al., 2014; Inselberg, 1985; Watson and Kasprzyk, 2017). Studies have shown that if parallel plots are interactive, first-time users can learn to use them effectively with 5-10 minutes of training (Johansson and Forsell, 2016; Siirtola and Räihä, 2006). Previous research has assessed whether users can evaluate multiple dimensions to complete a closed-form task with the plots, e.g. "Which one of the cars manufactured in 1982 has the slowest acceleration?" (Siirtola and Räihä, 2006). Our workshop differs in that we asked participants to use the information from the plots to make their own choices, so our results will reflect how practitioners used parallel plots to weigh tradeoffs and make judgements.

To enable the water managers to use parallel plots for subjective analyses, we created plots that supported extensive browsing, multiple selections, and comparisons between portfolios and across workshop activities. We used Tableau, a commercially-available business analytics program (Jones, 2014), to create a series of interactive worksheets on which participants could: hover over portfolios to get full decision and performance information, select one or more portfolios to highlight them, and enter portfolio IDs that changed the colors of those portfolios to register their choices for the activities described below. Critically, the workbooks allowed us to save their choices which both recorded them for later research analysis as well as allowed us to show managers how their choices changed (or did not change) over the course of the workshop.

Example results from optimizing the Eldorado Utility case study are presented in Figure 1. Briefly discussing the example results will facilitate readers' understanding of the information that water managers used during the charrette (described in the next section). As demonstrated below, we showed charrette participants the objectives and decisions together to provide all information about the portfolios and enable them to evaluate tradeoffs between different objectives while simultaneously exploring decision preferences. 


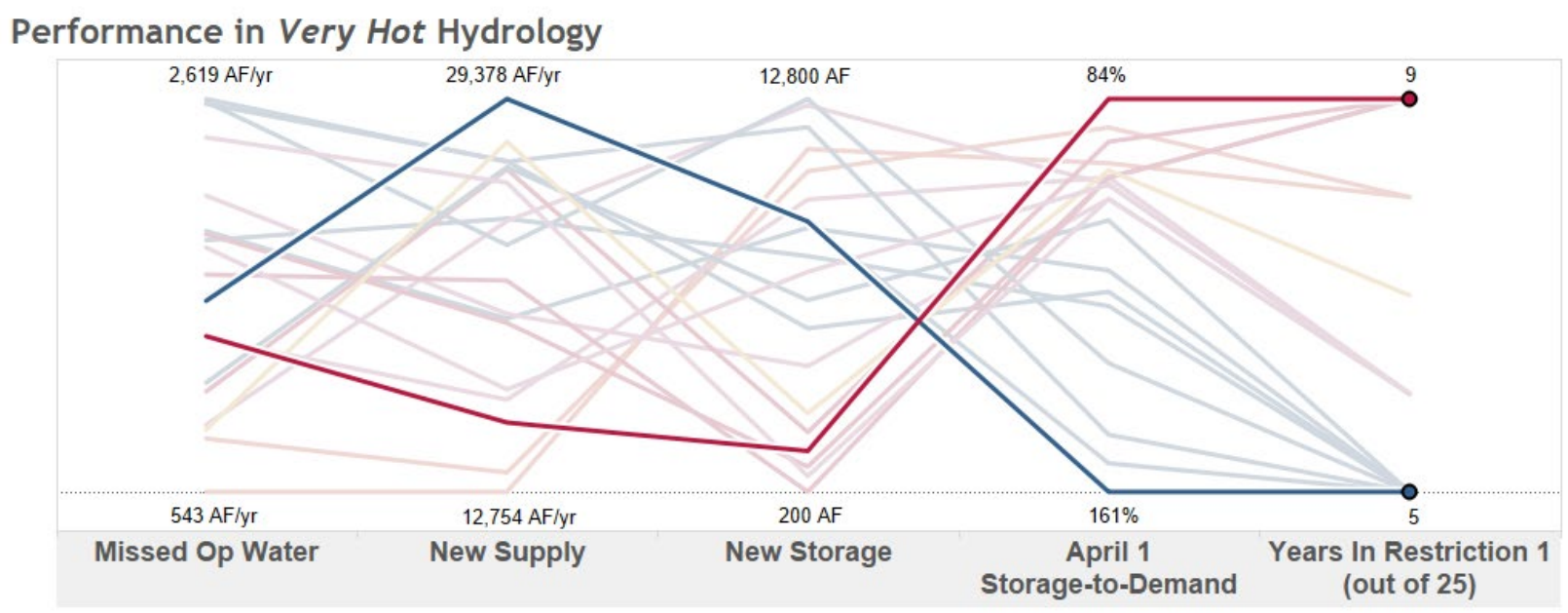

\section{Decision Levers}

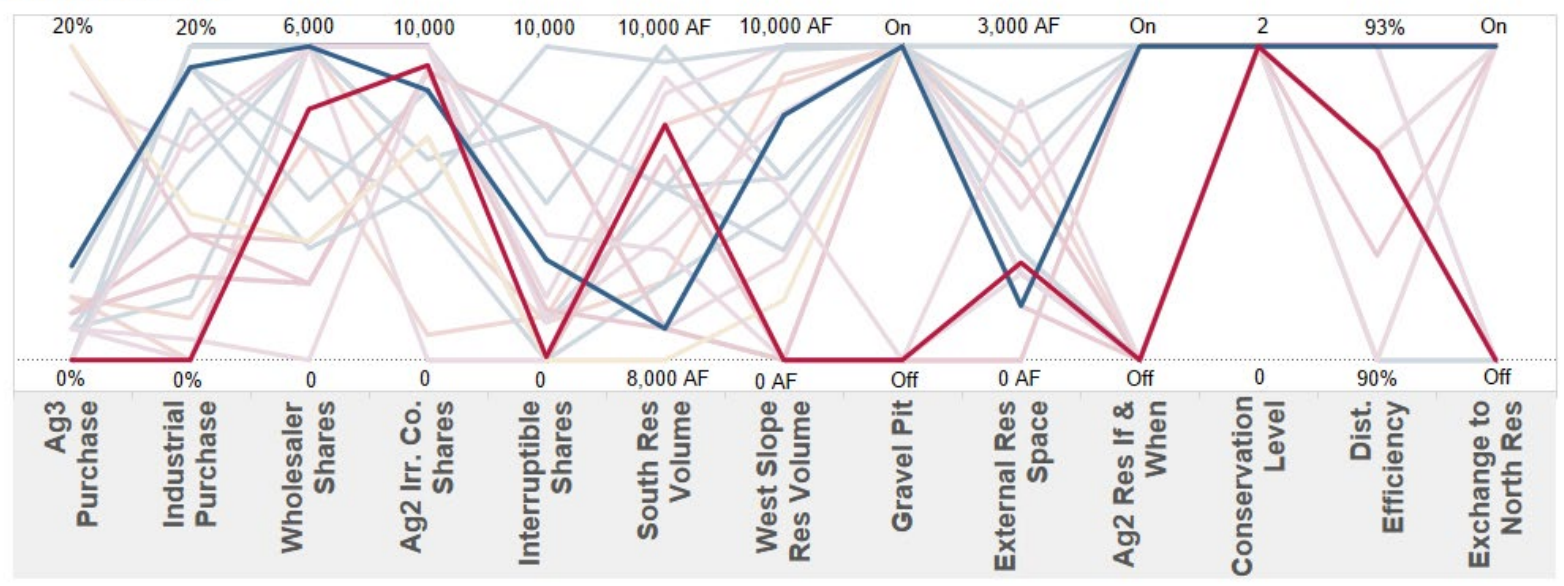

Figure 1. A screenshot of a Tableau worksheet that corresponds closely with what participants used in the charrette. Two portfolios are highlighted to demonstrate tradeoffs.

The plots in Figure 1 show 20 portfolios $^{4}$ that resulted from optimizing the Eldorado Utility case study using hydrology generated for a $4^{\circ} \mathrm{C}$-warmer (or "Very Hot") future. The top plot has five vertical axesone for each performance objective. Each of the lines connecting the axes is a portfolio. The vertical position at which a portfolio line crosses an objective axis denotes its performance, where lower intersection is better. (Note that the objectives and decision levers all have different numerical scales and we have normalized the values so that each dimension fully spans its axis.) The portfolios are colored based on how many years of Level 1 restrictions they produced (i.e. the performance on the

\footnotetext{
${ }^{4}$ The full tradeoff sets produced by the Eldorado Utility optimizations included approximately 1000 portfolios each (Smith et al., 2018). In order to make the most of limited workshop activity time, we only showed participants 20 predetermined alternatives that were hand-selected by researchers such that the subset captured a wide range of performance for each objective and clearly presented the system's performance tradeoffs.
} 
rightmost axis); blue lines all have five years in restriction, red lines all have nine years. Two portfolios are highlighted to demonstrate the tradeoffs presented in the plot. The blue portfolio has the best possible performance in April 1 Storage-to-Demand and Years in Restriction 1, has medium-poor performance in New Storage and Missed Op Water, and the worst possible performance in New Supply. These levels indicate the tradeoffs between reliability measures on the right two axes and other system performance considerations. Conversely, the red portfolio performs the worst in April 1 Storage-toDemand and Years in Restriction 1 but better, sometimes much better, than the blue portfolio in the other three objectives. Depending on Eldorado's preferences and priorities, they might choose portfolios with different performance characteristics.

The bottom plot shows decision lever attributes using a vertical axis for each of the 13 levers. As in the objectives plot, the lines connecting across axes are portfolios, and the position at which they intersect an axis denotes "how much" of a decision is included in the portfolio. The lower a portfolio line crosses, the "less" of that lever is present. Each portfolio line in the objectives plot has a corresponding line in the decision levers plot, so we can compare a few of the decisions led to the contrasting performance of the two highlighted alternatives described above.

\subsection{MOEA research charrette: June, 2016}

Step four of our application of ParFAIT, a research charrette, provided water managers with hands-on experience with MOEA-assisted optimization results. Our goals for the workshop were to:

1. provide exposure for the emerging tool;

2. observe managers' analyses of tradeoff information;

3. understand how managers relate the tradeoff information to their current needs and practices;

4. get feedback about what potential uses and barriers managers see in the tool;

5. learn about the general process of utilities adopting a new tool; and

6. report any opportunities for future research to meet the needs of practice.

Nine total participants from six Front Range utilities attended the workshop. The utilities represented a wide range of system sizes, and the individuals themselves also spanned a range of experience levels: 4 managers had over 16 years of experience in Front Range water management; 1 had between 11 and 15 years; 1 had between 6 and 10 years; and 3 had 0 to 5 years of experience. We also had participants with different roles within their respective agencies: four were at a management level and five were technical staff. This variety was helpful in getting different perspectives, and the presence of both 
technical and managerial practitioners was especially encouraging since having advocates at multiple levels of administration increases the likelihood of innovation uptake (Daniell et al., 2014).

\subsubsection{Charrette development}

Intense preparation and attention to charrette form, function, and sequencing made it possible for both participants and our team to approach the actual experience as a fun day of learning. Once we produced tradeoffs for the Eldorado system in multiple future scenarios (completed approximately three months prior to the charrette), we began the process of developing content and activities that could effectively introduce new concepts and provide an engaging hands on experience. To accomplish this, we undertook trials of content with unaffiliated water professionals and water researchers to learn about how MOEA novices reacted to various levels of information and visualization complexity. These dry runs helped shape the presentation of MOEA and testbed information, choices of activities, timing to complete them, and design of the Tableau workbooks.

The nine practitioner attendees were divided into three groups of three and seated at different tables. Each table had a facilitator, and the facilitators were chosen based on their familiarity with workshops and water management so that they could prompt and guide discussions in a neutral and knowledgeable way. Members of the core research team floated between groups to clarify technical or procedural questions. Each manager was given a laptop with the Tableau workbooks pre-loaded so that they could complete charrette activities independently. They then reflected on their individual efforts in small group discussions which are described in the Results section.

Data from this workshop includes the portfolio choices that managers made as well as discussions about the MOEA testbed tradeoffs, managers' analytical processes, utilities' planning approaches, tool adoption, potential for MOEAs overall, and workshop content. As such, we made sure to capture participants' portfolio choices but also took audio recordings and notes of each small group of managers. Having three types of information allowed us to ensure accuracy and produce results that synthesized both qualitative and quantitative responses. Additionally, post-workshop surveys recorded participants' overall perceptions of the usefulness of MOEA-assisted optimization.

The charrette used a detailed format, custom computer workbooks, and concrete tasks associated with the activities, all of which guided information flows between participants and researchers. Compared to our first ParFAIT workshop, which relied on free-form discussions about targeted topics to inform the direction of the overall project, this workshop was a relatively formal participation mechanism (Newig et 
al., 2008; Smith et al., 2017). However, the facilitated small group discussion sessions built into each activity captured open discussion and impressions from participants and allowed us to access subtleties of how utilities plan and operate and how managers relate to their systems. After the workshop we electronically surveyed participants about their perceptions of MOEA usefulness. This mixture of methods is fundamental to the success of charrettes (Gibson and Whittington, 2010). The incorporation of focus group-type activities and discussions was particularly useful for bridging the gap between researchers and practitioners because these interactions "provide a clear view of how others think and talk" (Morgan, 1993).

\subsubsection{Training and support materials}

In order for participants to fully engage in the workshop and provide researchers with thoughtful, relevant feedback about using the tool, they needed to be able to

1. understand why MOEA-assisted optimization has been proposed as a useful tool for water planning;

2. understand the concept of performance tradeoff sets;

3. have sufficient understanding and acceptance of the hypothetical utility, its supply and demand context, and its policies to be able to focus on tradeoffs;

4. understand and relate to the problem formulation and planning scenarios; and

5. effectively operate the Tableau workbooks and interact with parallel plots.

We covered these topics in a 90-minute introductory presentation. After explaining and taking questions about MOEAs and the testbed (content similar to that found in the Background section of this article), we held an interactive parallel plot training session.

In order to introduce parallel plots and tradeoff analysis, we created a simple multiobjective grocery shopping problem. Each participant used a Tableau worksheet set up identically to those that they would see in later activities that showed plots of performance and decision levers. We defined three conflicting objectives - minimize cost, maximize nutrition, and maximize pleasure - through which to optimize a set of eleven potential shopping items such as apples, ice cream, eggs, etc. As a group, we went through incremental closed-form exercises finding the least expensive shopping list, the most nutritious list, etc. The exercises required participants to analyze both the decision and objective plots and learn their interactive functions. The total training time was approximately 10 minutes. Questions 
were encouraged throughout, and no participants expressed any prolonged difficulty in interpreting the worksheets.

To support the managers in the day's activities, we gave them printed packets that included a diagram of the Eldorado Utility Planning Model, current and future utility demands, utility policies, descriptions of the decision levers and objectives, and descriptions of the different hydrologic scenarios. The diagram, reproduced in Figure 2, conveys the spatial and temporal complexity of the system using icons, colors, dates, and arrows. 


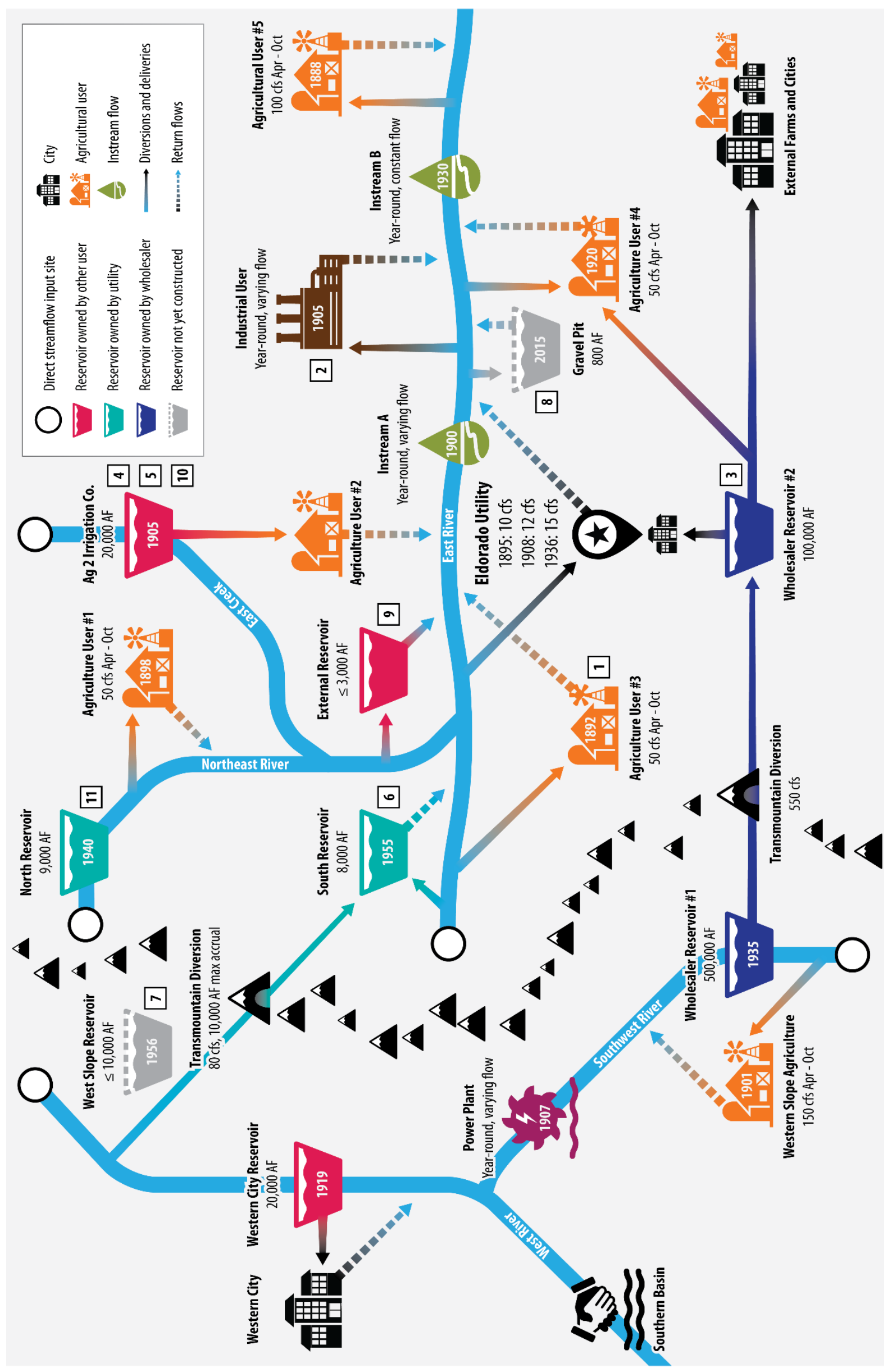


Figure 2. Diagram of the Eldorado Utility Planning Model given to charrette participants in their supporting materials packets. Icons, colors, arrows, and dates all convey spatial and temporal relationships between water users.

\subsubsection{Tradeoff activities}

The core of the charrette was organized into four main activities to test behavior with the tool in four different situations of increasing complexity. During each activity managers were given 10-15 minutes to independently explore tradeoffs presented in Tableau workbooks and apply their own logic (or dominance structure) to choose two portfolios.

The purpose of Activity 1 was to establish initial preferences and create a basis for managers to compare decision making with and without tradeoff information. The participants chose one of three portfolios developed heuristically by an expert "consultant" (researcher familiar with the model and case study). Each portfolio was characterized by its constituent decisions and its firm yield in historical hydrology, but no performance tradeoff information was offered. The chosen portfolios from this activity were brought back in Activity 4.

The Activity 2 sequence was designed to ease the managers into evaluating tradeoffs in complex plots, to create space for analyzing tradeoffs without the dominant influence of reliability (Smith et al., 2017), to have managers be able to explicitly compare their use of different amounts of information, and to do all of this without considering the likelihood or implications of climate change on Front Range supplies. In Activity 2, Exercise 1, participants were shown performance of 20 algorithm-optimized portfolios in a two-objective tradeoff (along with a plot of all of the portfolios' decisions) and asked to select two "portfolios of interest." The portfolios resulted from optimizing for historical hydrology, and were constrained to meet Eldorado's restrictions-based reliability policy. This was made clear to managers so they knew they did not have to worry about reliability in this first activity. In Activity 2, Exercise 2, managers were shown the same set of 20 portfolios as in Exercise 1, but now were given performance information in a four-objective tradeoff plot (along with the decisions plot). In Activity 2, Exercise 3, participants were shown the choices they made from Exercises 1 and 2 in one plot to compare the preferences they expressed with different amounts of tradeoff information.

Activity 3 introduced the frequency of Level 1 restrictions objective and perturbed hydrology. The exercises allowed researchers to probe how the presence of the Level 1 restrictions objective influenced participants' perceptions of other tradeoffs and added hydrologic challenges to their decision calculations. In Exercise 1, participants were shown 20 algorithm-optimized portfolios that resulted from optimizing in a $1^{\circ} \mathrm{C}$ warmer (Very Warm) future. To understand the implications of the different 
hydrology, managers referred to the informational packets where plots showing a slightly lower magnitude of peak runoff, slightly earlier peak timing, and similar regional flow variability. They were again asked to choose two portfolios and had to directly trade off reliability policy performance with the other four objectives from Activity 2. Exercise 2 was identical to Exercise 1 except that the 20 portfolios were from a set produced by optimizing for a $4^{\circ} \mathrm{C}$ warmer (Very Hot) future. This scenario had a much lower peak runoff magnitude, much earlier peak timing, and lower variability due to lower magnitude high-flow years.

Activity 4 was designed to emphasize to participants that portfolios developed for or optimized under specific futures may not be acceptable if the future is different than they planned for. Managers saw the exact same set of portfolios from Activity 3, Exercise 2, but now their performance in a set of varied hydrologic traces was shown (i.e., in a supply scenario that they were not optimized for). The set of 10 traces were drawn from all other scenarios, so performance reflected the portfolios' average performances in a wide set of futures. They were again asked to make two choices from this set, and while making the choices they could see how each portfolio performed in varied as well as $4^{\circ} \mathrm{C}$ hydrology (so they had two parallel plots of objectives and one plot of decision levers). Managers were also shown how their hand-crafted solution from Activity 1 performed in both scenarios and asked to reflect on how they felt about those portfolios, which were developed using historical hydrology. 
Table 2. Summary of charrette activities.

\begin{tabular}{|l|c|c|l|}
\hline Exercise & \# Objectives & \multicolumn{1}{|c|}{ Hydrology } & \multicolumn{1}{|c|}{ Description } \\
\hline Activity 1 & 0 & Historic & Choose 1 of 3 handmade portfolios \\
\hline Activity 2, Exercise 1 & 2 & Historic & Choose 2 portfolios based on 2 objectives \\
\hline Activity 2, Exercise 2 & 4 & Historic & Choose 2 portfolios based on 4 objectives \\
\hline Activity 2, Exercise 3 & 4 & Historic & $\begin{array}{l}\text { Compare choices from 2- and 4-tradeoff } \\
\text { exercises }\end{array}$ \\
\hline Activity 3, Exercise 1 & 5 & $1^{\circ} \mathrm{C}$ & $\begin{array}{l}\text { Choose 2 portfolios while evaluating explicit } \\
\text { tradeoffs between reliability and other } \\
\text { objectives }\end{array}$ \\
\hline Activity 3, Exercise 2 & 5 & $4^{\circ} \mathrm{C}$ & $\begin{array}{l}\text { Choose 2 portfolios while evaluating explicit } \\
\text { tradeoffs between reliability and other } \\
\text { objectives }\end{array}$ \\
\hline Activity 4 & 5 & Varied, $4^{\circ} \mathrm{C}$ & $\begin{array}{l}\text { Choose 2 portfolios with knowledge of how } \\
\text { they perform in both varied and extreme (4 }\end{array}$ \\
& & & hydrology; reflect on choices from Activity 1. \\
\hline
\end{tabular}

At the workshop, the managers played the roles of engineers at the hypothetical Eldorado Utility who were evaluating a new tool for its potential to enhance their upcoming long term planning process. Asking them to play a fictional role and use hypothetical (but realistic) tradeoff results helped participants to engage more candidly by distancing them from physical, social, and political pressures of their own systems. Similarly, for each activity, we asked the managers to choose two portfolios "to subject to further analysis" to avoid comparisons with the real-world, complex process that a utility undertakes to actually decide on one plan. It was important, however, to ask them to make individual choices; this forced them to really grapple with tradeoffs and to use some logical process, and thus created a more defined experience for them to discuss with researchers and each other.

For each exercise (except for Activity 2, Exercise 3 during which participants just compared two sets of portfolio choices), the group facilitators asked three main questions to prompt discussion:

A. What objective performances or tradeoffs made the two portfolios you chose interesting to you? 
B. What decision lever attributes made the solutions interesting to you?

C. Based on the objectives' performance, as a manager at your utility, do you think you would have chosen the same solutions to investigate further? Why or why not?

Questions A and B were designed to separate the ways that performance and decision levers impacted choices, and question $\mathrm{C}$ was designed to emphasize that we wanted the managers to choose freely but also provide as much real-world decision making context as they could.

\section{Results}

Throughout the day managers engaged with tradeoffs, facilitators, and each other. They took the purposes of the workshop seriously and combined openness to the activities with reflections about their own agencies' planning contexts. As we prompted them with specific concepts, they each interpreted and applied them differently. A result of this was that, across nine managers, the portfolio selections often varied widely and sometimes the processes they used to make them also varied significantly. Rather than report each individual's choices and processes, below is a description of common themes and examples of how logic changed over the course of the day.

\subsection{Managers' use of tradeoffs}

Within this section about how managers used tradeoff information, there are four subsections. The first discusses findings from Activity 2, which presented managers with first two, then four objectives to analyze. Brief synopses of two managers' decision processes and how they relate to dominance structuring are included. The second subsection of results is based on Activity 3 , which introduced a fifth objective (Level 1 restrictions) and two new, more hydrologically challenging scenarios. Subsections three and four present findings that emerged throughout all four activities.

\subsubsection{Tradeoffs in two objectives vs. in four objectives}

In Activity 2, Exercise 1, where participants saw tradeoffs in two objectives, three general strategies emerged for choosing portfolios of interest. Five managers weighted performance in the objectives equally, two performed cost-benefit analyses between the two objectives, and two managers prioritized performance in one objective over the other. Figure 3 shows the results of Manager B4's cost-benefit analysis. The manager started by picking the portfolio with the least storage, then worked incrementally up the New Storage axis to find out how much better the performance in Missed Opportunity could get. The manager ultimately tried to find the portfolios where the tradeoff was "reasonable"- where the 
sacrifice in one objective came with a worthwhile gain in the other. This process is an example of the creation of a dominance structure; the manager initially screened alternatives based on the lexicographic decision rule (where there is a most important attribute) and then iteratively applied the addition of utilities rule to select portfolios (Montgomery, 1983).
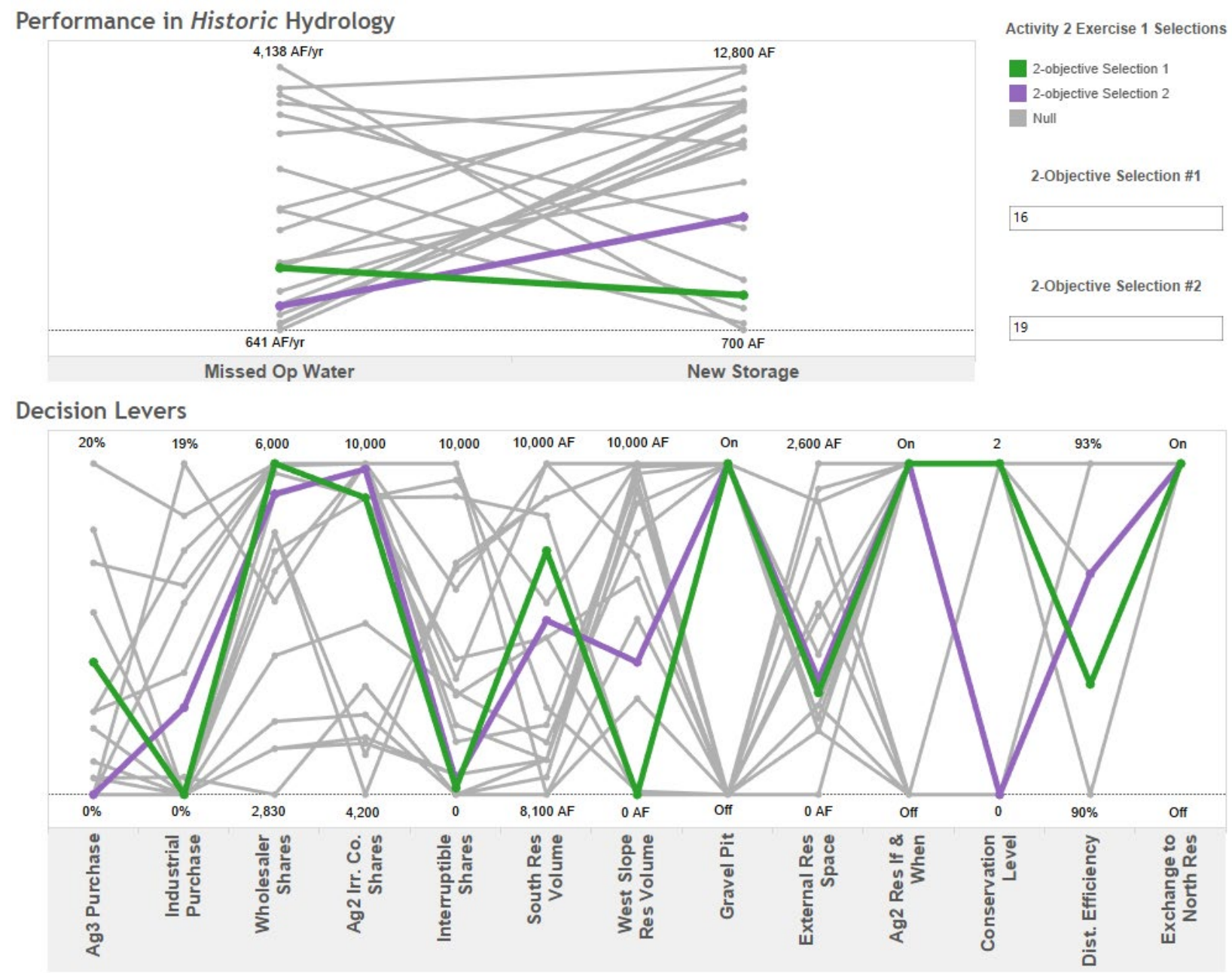

Figure 3. Screenshot of manager B4's portfolio selections for Activity 2, Exercise 1.

In Activity 2, Exercise 2, managers were asked to make two selections from the same set of portfolios that they saw in Exercise 1, but they did so with performance tradeoffs in four objectives instead of just two (so it was possible to choose the same portfolios in both exercises). Indeed, two managers chose the exact same portfolios as they did in Exercise 1, three managers chose one matching portfolio, and the other four participants chose two new solutions when presented with more tradeoff information. In Activity 2, Exercise 3, where managers were shown the two sets of choices they made, the managers who had identical sets of choices said that they used the same criteria in the second exercise as they did 
first. This is a good reminder that new tools and new information do not necessarily result in changed preferences or different choices; MOEA tradeoffs may also reinforce existing cognitive heuristics or increase confidence in decisions depending on the nature of the tradeoffs and how managers use a priori judgements to create dominance structures.

For the seven managers who chose at least one new portfolio in Exercise 2, they tended to balance their two choices against each other. For example, if they chose one portfolio that was "middle of the road" across the objectives, they allowed themselves to choose a second portfolio that prioritized one objective regardless of whether it performed poorly in another. Figure 4 shows Manager B2's two selections. For the first choice (blue), the manager balanced across the objectives (i.e. he collapsed performance attributes using the addition of utilities rule); the second choice (maroon) resulted from screening lexicographically on New Storage performance and then deemphasizing Missed Op to support the dominance of the chosen portfolio. When discussing the process used to make choices with two tradeoffs versus four, this manager said, "More objectives is better in terms of understanding the system and its performance. I assume that at some point it gets too noisy, but I definitely see value in going from two to four. Even if I end up prioritizing one or two objectives, it helps to see the implications that has on the others." 

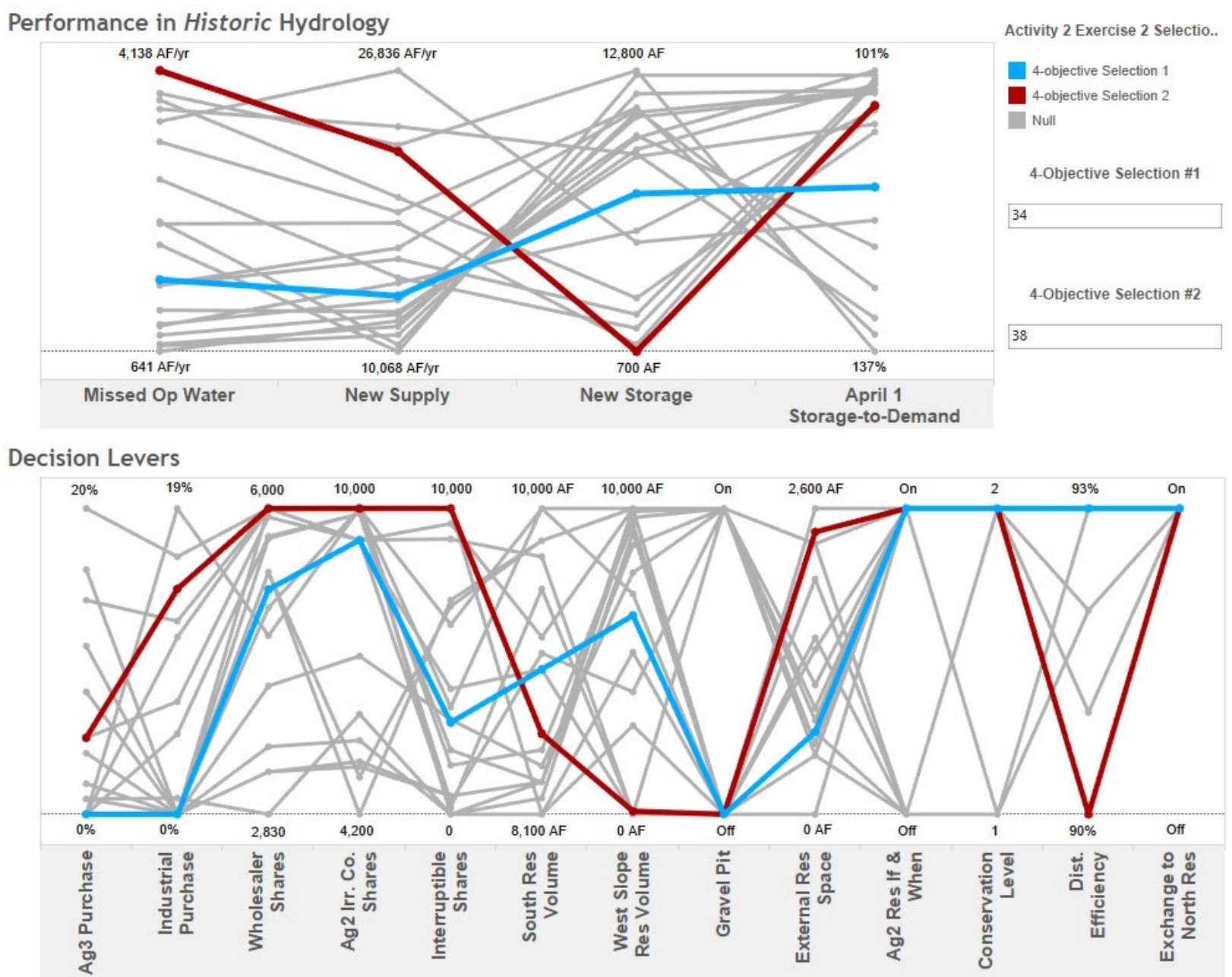

Figure 4. Screenshot of manager B2's portfolio selections for Activity 2, Exercise 2.

\subsubsection{Use of the Level 1 Restrictions objective}

The tradeoff analyses from Activity 2 included only portfolios that complied with Eldorado's restrictionsbased reliability criteria (defined as not exceeding 5 years in Level 1 restrictions over the 25-year simulation). This condition was explicitly conveyed to participants, and they were not presented with an objective that measured performance with respect to restrictions. By omitting an objective about restriction performance, the participants were able to consider their performance and decision preferences without directly grappling with level-of-service or policy consequences. Once frequency of restrictions was introduced as the fifth objective in Activity 3, all participants used it as their initial screening criterion. Additionally, both exercises in this activity used a climate change-perturbed hydrology: the portfolios in Exercise 1 resulted from a $1^{\circ} \mathrm{C}$ warmer scenario, and portfolios in Exercise 2 resulted from a $4^{\circ} \mathrm{C}$ warmer scenario. 
Though they had many options that resulted in only two years of restrictions, five of nine managers considered portfolios that exhibited from three to five years in Level 1 Restriction in Activity 3, Exercise 1. However, only two managers ended up choosing portfolios with three or more years in restriction while none of the other seven managers found that the performance gains in other objectives warranted the extra years. Seven of nine participants expressed satisfaction with the performance and decision lever balances they were able to strike, and two expressed concerns that their decision preferences seemed less effective in the warmer scenario.

While all managers chose to perform better than Eldorado's reliability policy criteria in Activity 2 Exercise 1, it was difficult to meet the criteria in Exercise 2 because the portfolios were evaluated in a hydrologically challenging $4^{\circ} \mathrm{C}$ warmer future; there were no portfolios that had fewer than five years in Level 1 restrictions (the maximum allowed by Eldorado's policy). All portfolios that met the criteria required great sacrifices in at least two other objectives. For the three participants who stayed within the criteria, two focused on performance in one other objective and one tried to balance three other objectives within the compliant portfolios. Of the six other managers, four determined that one or two extra years in restrictions was worth the gains in other objectives, noting that this thinking would trigger policy discussions with their decision making boards- "this tool would be really useful in demonstrating just how much service we would have to give up in order to avoid unpopular storage or supply decisions." Two managers felt that once the climate had warmed by $4^{\circ} \mathrm{C}$, norms would have changed, lawns would have disappeared, and people wouldn't expect the same levels of service that they had seen in the past, so they chose portfolios with nine years in restrictions and were able to avoid big storage projects. So, given difficult tradeoffs, three managers made painful concessions to comply with restrictions policy, four bargained on (relatively) small policy deviations thinking that the trade could become the focus of broader negotiations, and two managers reframed the problem in order to justify alternative(s) that they considered superior.

\subsubsection{More information, divergent choices}

In analyzing all managers' specific portfolio choices over the course of the day, we found that as more information was added and tradeoff experience increased, the group's choices started to diverge. Three participants made identical choices to one another in Activity 2, Exercise 1; the same was true in Activity 2, Exercise 2. The sets of participants and the choices were different, though, and there were no correlations with experience level of the participants or size of utility. Overall, seven different portfolios were chosen in Exercise 1 and five different portfolios were chosen in Exercise 2 (out of 18 total choices 
made per exercise: 2 choices for each of 9 participants). There were no sets of identical choices in Activities 3 and 4. In Activity 3, Exercises 1 and 2, 10 and 12 different portfolios were chosen, respectively, out of 18 total choices that were made for each exercise. Finally, 12 different portfolios were chosen in Activity 4 (when participants were prompted to select portfolios while evaluating their performance in two different futures simultaneously).

Adding the Level 1 Restrictions objective and using more challenging hydrology resulted in more divergent choices than those with historical hydrology and only two or four objectives in play. The finding that more information can lead to a wider variety of choices is perhaps not surprising because there are more avenues for creating dominance structure. However, it is worth considering how increasing information and greater divergence would affect a real-world planning process that involves several levels of scrutiny by many employees, decision makers, and the public. While this workshop focused on how individuals perceived and worked with high dimensional tradeoffs, more formal preference elicitation and application via Multicriteria Decision Making (MCDM) could be helpful when employing an MOEA in formal planning settings (Triantaphyllou, 2000). MCDM encompasses a variety of techniques that are designed to systematically incorporate different perspectives and values into the process of selecting among alternatives when there is no clear optimal solution. Here, a posteriori MCDM method such as the Analytical Hierarchical Process (AHP) (Saaty, 1980) would be appropriate because its method of pairwise comparison yields calculations of weights after the alternatives have already been generated (i.e., post optimization).

\subsubsection{Using objectives vs. decisions to make choices}

For all participants, objective performance was the main focus when choosing portfolios of interest. Whether they tried to balance across all objectives or prioritized a subset of them, managers tended to structure preferences primarily around performance. From the subset of portfolios that had satisfactory performance, they would sometimes try to find the ones that had decisions they preferred. This secondary screening based on decision levers almost always centered on avoidance or pursuit of certain types of storage and/or moderate or aggressive use of soft path options (e.g. interruptible shares or conservation). One manager who was focusing on portfolios that minimized New Storage was also concerned that some portfolios that performed relatively well in this objective could actually be hard to pursue because they had small amounts of storage in multiple locations (e.g. a medium expansion of the South Reservoir and building a small West Slope Reservoir). Another manager noted that they were all "starting with performance and then looking at the levers. We want to see the results first and then 
work backwards. That's not how a lot of things are done in reality; normally we look at sets of levers and then model outcomes." Another reflected that "if you pick totally on performance and ignore decision levers, you pick solutions that you wouldn't have chosen just based on decisions; conversely, if you pick based on decisions first, you'll probably be surprised about their poor performance."

Use of decision levers to make choices varied across the activities. In the first exercise with two objectives, four of nine participants considered decision levers, while only three of nine did so in the four-objective exercise and the $1^{\circ} \mathrm{C}$ warming exercise. This slight drop off may at least partially be due to the fact that complexity was added via number of tradeoffs and (in the case of the $1^{\circ} \mathrm{C}$ exercise) new hydrology. These changes may have taken up some extra cognitive bandwidth for participants, as suggested by one manager: "How many objectives is too many? What can we handle versus what do you miss if you don't include all of the objectives?" In the $4^{\circ} \mathrm{C}$ scenario, seven of nine participants looked at decision levers while making choices. One reason for this could be the fact that only hydrology changed between $1^{\circ} \mathrm{C}$ and $4^{\circ} \mathrm{C}$. Besides participants' greater comfort with the complex data visualizations, the increased consideration of decision levers in $4^{\circ} \mathrm{C}$ was related to the fact that limiting the number of years in restrictions required large sacrifices in New Storage and/or New Supply. In coming to terms with this tradeoff, managers tried to reduce reliance on storage or permanent agriculture dry-up, but ended up having to weigh this tradeoff against meeting reliability criteria.

Whether or not they used decision lever characteristics to choose portfolios of interest, all participants expressed surprise and curiosity about the relationships between decisions and performance.

Comments like the ones below came up frequently throughout the day:

- Why do the decisions change so much but give me similar performance?

- Why do very similar portfolios perform so differently?

- Why didn't this certain lever ever get turned on in the portfolios I was focusing on?

- Why can't I have this performance but with more conservation?

- What are the differences in decisions with these two extremes in performance?

- Why aren't these levers ever turned on? Are they not effective?

One participant wondered: "Is the impact that subtle changes in decisions can have on performance something that utilities miss in the way we currently do things?" 


\subsection{Opportunities and challenges to using MOEA-assisted optimization}

\subsubsection{Opportunities}

Over the course of the exercises, as well as during the large group discussion, participants noted how the type of information produced by MOEA-assisted optimization could be used to enhance their utilities' long term planning processes. Managers proposed two uses that support the technical foundations of planning: to help staff understand complex dynamics of their supply sources and infrastructure interactions, and to use surprising dynamics to interrogate the accuracy of their planning models. One manager focused on the public participation aspect of planning, suggesting the results could be used to show community members how much service they would have to give up (via more frequent restrictions) in order to avoid unpopular and expensive infrastructure projects. Another manager brought up the council-level component of planning when considering how the tradeoffs could help make the case for changing reliability policy to decision makers or board members.

One participant had ideas to tie the tool to two common water utility planning concepts: triple bottom line assessments and robust decisions. Regarding the triple bottom line, the manager wondered whether each lever could be scored by knowledgeable utility staff based on its economic, social, and environmental costs. These scores could then be used as objectives and minimized by the MOEA. Although this scoring would be somewhat qualitative, subjective, and may possibly under- or overestimate costs of specific projects that have not been thoroughly studied, connecting tradeoffs directly to fundamental utility planning concepts may prove useful. Utilities are also concerned with elucidating robust decisions, or those that support good system performance in a wide range of climatic futures. The manager suggested that finding specific decisions that featured prominently in portfolios that achieved desired performance balance in multiple planning scenarios could mean that they are robust.

One participant thought it might be useful to give each portfolio an area under the curve score based on the objectives as a way to objectively compare portfolios. Another reflected that with the current trend of relying on algorithms make choices based on a priori weighting, this application of optimization was appealing because it still focuses on human decision making but with extra information.

Our post-workshop survey asked participants two questions via email:

1. How useful do you think the quantitative tradeoff information produced by the MOEA would be for learning about your utility's system? 
2. How useful do you think the quantitative tradeoff information produced by the MOEA would be for enhancing your utility's approach to long term planning?

The scale for responses was from 1 (not useful) to 5 (very useful). All responses for being useful for system learning and planning were 3 or above out of 5 , with an average rating of 3.7 for useful for system learning, and 3.9 for planning.

\subsubsection{Challenges}

The challenges brought up by participants fell into three general categories: modeling, personnel, and conveying process and results. A manager from a utility that had just used MOEA-assisted optimization in their planning asked a simple question: "How much do you trust your model?" When the participant's agency was confronted with surprising tradeoff results, in some cases the results provided verifiable, novel system understanding; in other cases, they were the product of model errors. This issue was exacerbated when existing models were run in extreme hydrologic and portfolio combinations, and underscored the importance of having system and project experts review portfolios. On the topic of modeling, other managers noted that a utility has to have the right kind of planning model- a model that provides a useful timestep resolution, an appropriate level of internal system detail and external context, and that can run reasonably quickly.

Managers from the two utilities that had MOEA experience agreed that training staff to understand the tradeoff results and maintaining those skills was a struggle. Interacting with tradeoff visualizations and using the information to reason about a problem requires a particular cognitive approach, and the managers reported that for many members of their teams, seeing results from their consultants once a month required a review at each meeting (the managers did not specify how the tradeoffs were visualized during their previous planning studies). Furthermore, to continue to see benefits from using the tool, one or more staff members would need to maintain proficiency with the results and potentially be able to produce new optimization runs. The managers also said that when technical staff who had often spent years developing certain projects were confronted with portfolios that performed well but did not incorporate their projects, discussions and negotiations could become difficult. While this workshop was not designed to analyze the details of how these two utilities used MOEAs, conducting indepth interviews with their staff would likely result in valuable insights for both technical and social science research communities. 
The inner workings of the MOEA, the process of employing one, and the results it produces are complex. In order for a utility to use one, one or more staff would have to make considerable effort to build understanding about the tool within the agency. Because the results are so complex, technical staff also must simplify the message to decision makers without sacrificing confidence in the tool or alienating their audience. Managers with and without MOEA experience agreed that this is a difficult task. A critical component of understanding, simplifying, and conveying the results is having visualizations that are as easy as possible to understand. A manager suggested that this is so important that it may be worth consulting someone with training in data visualization for input.

\subsection{Adoption of new tools}

Researchers asked participants to discuss their utilities' experiences with the process of adopting new tools. The process starts when technical staff become aware of new tools. According to these managers, the water management industry is bombarded with great ideas and they have to sift through them and think about what they can apply. Sometimes the ideas come from consultants, e.g. through Integrated Water Resources Plan (IWRP) requests-for-proposals, and sometimes the ideas come from conferences, workshops, and/or co-production with researchers. They agreed that case studies of real-world applications are helpful for opening utilities up to new tools, and the cases are especially influential when they involve neighboring utilities. Managers from one of the utilities that had used an MOEA said it took sustained effort to convince upper management to become that case study.

When a tool is being considered by a utility, many conditions must be met before it can be adopted. Managers reported that getting broad acceptance is very challenging; it can take years, and requires at least one champion within the agency, but preferably two because this lends credibility and force to the proposal. However, once technical staff have boiled down the details and shown need for, and potential benefit from, the tool, upper managers and boards trust them to perform the innovative analyses. However, in order for staff to buy in, they need to understand the background and "guts" of using the new tool, they need to be heavily involved in developing and integrating it, and they need to have access to technical assistance once they are using it.

One manager offered a distilled version of the above: "We need proof that the tool works, trust in the people proposing it, and we need evidence that it is useful and usable." In other words, the tool needs to be credible, legitimate, and salient (Cash et al., 2003). 


\subsection{Real-world planning and decision making context}

During small group discussions, participants answered the specific questions posed by facilitators, but also had discussions among themselves that provided insight into how utilities think about difficult planning questions. One such conversation was around level of service versus customer billing rates. If utilities try to avoid costly infrastructure as much as possible, rates don't have to go up to pay for it. But, in the long term future when Colorado utilities will potentially be even more dependent on wet years to recover system storage, the only way to take advantage of that is to have adequate storage capacity. If avoiding infrastructure means greater frequency of restrictions, that can lead to long-term reduced utility revenues, prompting rates to slowly creep up anyway. Once rates increase, they will never go back down, so how do customers want to experience this? A manager summarized the tradeoff by asking "where do you want the pain to be in your system- low reliability or high rates?"

Another group discussed the drawbacks of conservation and demand hardening (Howe and Goemans, 2007). For smaller service areas, conservation has very little impact compared to the yield of new supply, and may only displace the need for new supply in the short term. Conservation is really most effective at saving water used on lawns in wetter years; in dry years, watering is already reduced via restrictions. Once conservation sets off demand hardening or years of restrictions creates a "drought shadow" (persistence of lower demand than pre-drought levels), restrictions don't produce as much savings and deeper, more invasive restrictions become necessary. This effect was recently further documented in Dilling et al (2018).

We also learned about some practical realities of how utilities make decisions. Managers noted that opportunism plays a big role in determining which projects go forward and when; e.g., if a cable company is ripping up a road, a utility will go ahead and fix leaks in the nearby pipes. Another major factor for whether utilities take on a project is whether it involves federal permitting; agencies strongly prefer not to undertake this process which commonly takes more than 10 years, millions of dollars, and relies on highly uncertain outcomes. Sunk costs also motivate utility decision making; any projects that have already seen some investment may be pursued regardless of optimization results.

In the large group discussion at the end of the day, several managers lamented the realities of planning at five-year intervals. Long term planning has become such an undertaking that the preparation involved in creating a plan can take many months, after which the staff need time to recuperate as the planning process itself is so arduous. Once normal staff functioning resumes, it may be time to start thinking 
about the next plan. Researchers should consider how existing their current expertise or future research can contribute tools or processes that support sustained planning.

\section{Conclusions}

In the charrette tradeoffs often, but not always, influenced managers' construction of preferences. It was clear that the ability to directly compare alternatives across several dimensions helped managers reason out a dominance structure; sometimes they iterated until they found a satisfying alternative and sometimes they worked backward to justify a choice. In a few responses, though, managers simply applied their preferences to the set of options they were given and chose, e.g., the portfolio with the least New Storage. This suggests that the other objectives were not compelling enough to warrant compromises, and/or that additional information does not always affect core priorities. On another level, managers often used the opportunity to make two selections to balance their indecision and actually seemed to trade performance between their two choices.

Beyond using tradeoffs to justify their own selections, managers came up with ways that tradeoff sets could bring justification to broader aspects of the utility planning process. They suggested that the tradeoffs could support policy negotiations with boards or councils as well as communications with the public. If the tradeoffs revealed that a minor relaxation of reliability criteria could drastically reduce reliance on new storage, that information could be a valuable point of discussion. Similarly, if a community opposed a specific project, tradeoffs could explicitly show sacrifices that would be necessary to avoid it. Several managers noted that the ability to choose performance priorities and then learn what portfolios and decisions contribute to the performance offers a new, potentially valuable way of approaching the planning process. This feedback from the participants clearly points to how MOEAs can enhance many aspects and phases of planning.

Though there are challenges to incorporating MOEAs, e.g. appropriate and trustworthy modeling, maintaining tradeoff fluency, and securing technical support, many managers found their distinct capabilities appealing. They appreciated the ability to see relationships between objectives. We heard that it was refreshing to be able to combine an optimization tool with human reasoning- that the tradeoffs empowered managers instead of diminishing their input.

The results from this charrette suggest to us at least two promising avenues for further technical research to support MOEAs for long term water utility planning. We draw the first from what we heard about the relationships between decision levers and objectives and how each traditionally influence 
planning. Generally, utilities devise portfolios to see how they perform; in the workshop, a manager pointed out that they were choosing performance and then seeing which levers that entailed. This shift prompted many questions about what influence one or more levers had on performance. Future research that quantifies relationships between levers and performance could increase the value of tradeoff sets to the agencies that use MOEAs.

The other avenue is to begin exploring the role that MOEA tradeoff sets can play in sustained planning. Can the system information attained through the tradeoffs and the large set of potential portfolios form the basis of adaptation? As supply or demand information solidifies or infrastructure projects do or do not come to fruition, can future actions be informed by tradeoffs and portfolios that have already been generated, thus reducing the burden of planning cycles?

The MOEA research charrette was an effective approach to engaging with water managers about the potential for MOEAs to enhance long term water utility planning. Through the workshop we exchanged and created new knowledge with our participants. This success was possible through the application of the Participatory Framework for Assessment and Improvement of Tools (ParFAIT), which created a roadmap for research activities and structured the relationships with our practitioner partners. This transdisciplinary, participatory venture resulted in deeper understanding of water management context, inspired future research directions, and forged new links between academia and practice.

\section{Acknowledgements}

This work was funded by the National Oceanographic and Atmospheric Administration (NOAA) through their Sectoral Applications Research Program (SARP), grant \# NA14OAR4310251. We would like to thank the following water supply agencies for contributing their time and expertise to this study: City of Aurora, City of Boulder, Colorado Springs Utilities, Denver Water, City of Fort Collins, and Northern Water. We thank Western Water Assessment (a NOAA-funded Regional Integrated Sciences and Assessment project) for assistance in designing and facilitating the process for the workshop discussed. Finally, we thank our reviewers for their insights and suggestions which strengthened this paper. 


\section{References}

Abowitz, D.A., Toole, 2010. Mixed Method Research: Fundamental Issues of Design, Validity, and Reliability in Construction Research. Journal of Construction Engineering and Management 136, 108-116. https://doi.org/10.1061/(ASCE)CO.1943-7862.0000026

Aristotle, 1920. Ethica Nicomachea, Oxford Classical Texts. Oxford University Press, Oxford, New York.

Basdekas, L., 2014. Is Multiobjective Optimization Ready for Water Resources Practitioners? Utility's Drought Policy Investigation. Journal of Water Resources Planning and Management 140, 275276. https://doi.org/10.1061/(ASCE)WR.1943-5452.0000415

Cash, D.W., Clark, W.C., Alcock, F., Dickson, N.M., Eckley, N., Guston, D.H., Jäger, J., Mitchell, R.B., 2003. Knowledge systems for sustainable development. PNAS 100, 8086-8091. https://doi.org/10.1073/pnas.1231332100

Caulfield Jr., H.C., Evans, N., Flack, J.E., Grigg, N., Hendricks, D., Labadie, J., McWhorter, D., MorelSeytoux, H., Raley, W., Young, R., Milliken, J.G., 1987. Voluntary Basinwide Water Management South Platte River Basin (No. 133). Colorado Water Resources Research Intitute, Fort Collins, Colorado.

Connolly, T., Reb, J., 2012. Regret aversion in reason-based choice. Theory and Decision 73, 35-51. https://doi.org/10.1007/s11238-011-9269-0

CSU, 2017a. Integrated Water Resources Plan Final Report. Colorado Springs Utilities, Colorado Springs.

CSU, 2017b. Integrated Water Resources Plan Technical Memo 21: Portfolio Development and Evaluation. Colorado Springs Utilities, Colorado Springs.

Daniell, K.A., Coombes, P.J., White, I., 2014. Politics of innovation in multi-level water governance systems. Journal of Hydrology 519, 2415-2435. https://doi.org/10.1016/j.jhydrol.2014.08.058

Díez, E., McIntosh, B.S., 2009. A review of the factors which influence the use and usefulness of information systems. Environmental Modelling \& Software 24, 588-602. https://doi.org/10.1016/j.envsoft.2008.10.009

Dilling, L., Daly, M.E., Kenney, D.A., Klein, R., Miller, K., Ray, A.J., Travis, W.R., Wilhelmi, O., 2018. Drought in urban water systems: Learning lessons for climate adaptive capacity. Climate Risk Management. https://doi.org/10.1016/j.crm.2018.11.001

Dilling, L., Lemos, M.C., 2011. Creating usable science: Opportunities and constraints for climate knowledge use and their implications for science policy. Global Environmental Change 21, 680689. https://doi.org/10.1016/j.gloenvcha.2010.11.006

Elkington, J., 2004. Enter the Triple Bottom Line, in: Henriques, A., Richardson, J. (Eds.), The Triple Bottom Line: Does It All Add Up. Earthscan, London, pp. 1-16.

Fleming, P.J., Purshouse, R.C., Lygoe, R.J., 2005. Many-Objective Optimization: An Engineering Design Perspective, in: Coello, C.A.C., Aguirre, A.H., Zitzler, E. (Eds.), Lecture Notes in Computer Science. Springer Verlag, pp. 14-32.

Gibson, E.G., Whittington, D.A., 2010. Charrettes as a Method for Engaging Industry in Best Practices Research. Journal of Construction Engineering and Management 136, 66-75. https://doi.org/10.1061/(ASCE)C0.1943-7862.0000079

Green, S.D., Chung-Chin, K., Larsen, G.D., 2010. Contextualist Research: Iterating between Methods While Following an Empirically Grounded Approach. Journal of Construction Engineering and Management 136, 117-126. https://doi.org/10.1061/(ASCE)CO.1943-7862.0000027

Hadka, D., Reed, P., 2013. Borg: An Auto-Adaptive Many-Objective Evolutionary Computing Framework. Evolutionary Computation 21, 231-259. https://doi.org/doi:10.1162/EVCO_a_00075

Hadka, D., Reed, P.M., Simpson, T.W., 2012. Diagnostic Assessment of the Borg MOEA for ManyObjective Product Family Design Problems, in: Evolutionary Computation (CEC), 2012 IEEE Congress On. Brisbane. https://doi.org/10.1109/CEC.2012.6256466 
Herman, J.D., Zeff, H.B., Reed, P.M., Characklis, G.W., 2014. Beyond optimality: Multistakeholder robustness tradeoffs for regional water portfolio planning under deep uncertainty. Water Resour. Res. 50, 7692-7713. https://doi.org/10.1002/2014WR015338

Hobbs, G.J., 2004. Citizen's Guide to Colorado Water Law, 2nd ed. Colorado Foundation for Water Education, Denver, Colorado.

Howe, C.W., Goemans, C., 2007. The simple analytics of Demand Hardening. American Water Works Association. Journal; Denver 99, 24-25.

Inselberg, A., 1985. The Plane with Parallel Coordinates. The Visual Computer 1, 69-91.

Johansson, J., Forsell, C., 2016. Evaluation of Parallel Coordinates: Overview, Categorization and Guidelines for Future Research. IEEE Transactions on Visualization and Computer Graphics 22, 579-588. https://doi.org/10.1109/TVCG.2015.2466992

Jones, B., 2014. Communicating Data with Tableau: Designing, Developing, and Delivering Data Visualizations. O'Reilly Media, Inc.

Keim, D.A., Mansmann, F., Schneidewind, J., Ziegler, H., 2006. Challenges in Visual Data Analysis. IEEE Computer Society, London, UK, pp. 9-16.

Kollat, J.B., Reed, P.M., 2007. A Framework for Visually Interactive Decision-making and Design using Evolutionary Multiobjective Optimization (VIDEO). Environmental Modelling \& Software 22, 1691-1704.

Kularathna, U., Rhodes, B., Ravalico, J., Rowan, T., Tan, K.S., 2015. Optimisation modelling applications for Melbourne's water resource management. 36th Hydrology and Water Resources Symposium: The art and science of water 649.

Liu, S., Maljovec, D., Wang, B., Bremer, P.T., Pascucci, V., 2017. Visualizing High-Dimensional Data: Advances in the Past Decade. IEEE Transactions on Visualization and Computer Graphics 23, 1249-1268. https://doi.org/10.1109/TVCG.2016.2640960

Maier, H.R., Kapelan, Z., Kasprzyk, J., Kollat, J., Matott, L.S., Cunha, M.C., Dandy, G.C., Gibbs, M.S., Keedwell, E., Marchi, A., Ostfeld, A., Savic, D., Solomatine, D.P., Vrugt, J.A., Zecchin, A.C., Minsker, B.S., Barbour, E.J., Kuczera, G., Pasha, F., Castelletti, A., Giuliani, M., Reed, P.M., 2014. Evolutionary algorithms and other metaheuristics in water resources: Current status, research challenges and future directions. Environmental Modelling \& Software 62, 271-299. https://doi.org/10.1016/j.envsoft.2014.09.013

Matrosov, E.S., Huskova, I., Kasprzyk, J.R., Harou, J.J., Lambert, C., Reed, P.M., 2015. Many-objective optimization and visual analytics reveal key trade-offs for London's water supply. Journal of Hydrology 531, Part 3, 1040-1053. https://doi.org/10.1016/j.jhydrol.2015.11.003

Montgomery, H., 1983. Decision Rules and the Search for a Dominance Structure: Towards a Process Model of Decision Making. Advances in Psychology, Analysing and Aiding Decision Processes 14, 343-369. https://doi.org/10.1016/S0166-4115(08)62243-8

Morgan, D.L., 1993. Successful Focus Groups: Advancing the State of the Art. SAGE Publications.

Mortazavi, M., Kuczera, G., Cui, L., 2012. Multiobjective optimization of urban water resources: Moving toward more practical solutions. Water Resources Research 48. https://doi.org/10.1029/2011WR010866

MWD, 2015. Integrated Water Resources Plan. Metropolitan Water District, Los Angeles, CA.

Newig, J., Gaube, V., Berkhoff, K., Kaldrack, K., Kastens, B., Lutz, J., Schlußmeier, B., Adensam, H., Haberl, H., 2008. The Role of Formalisation, Participation and Context in the Success of Public Involvement Mechanisms in Resource Management. Syst Pract Action Res 21, 423-441. https://doi.org/10.1007/s11213-008-9113-9

Nicklow, J., Reed, P., Savic, D., Dessalegne, T., Harrell, L., Chan-Hilton, A., Karamouz, M., Minsker, B., Ostfeld, A., Singh, A., Zechman, E., 2010. State of the Art for Genetic Algorithms and Beyond in 
Water Resources Planning and Management. Journal of Water Resources Planning and Management 136, 412-432.

P. O. Abbott, 1985. Description of Water-Systems Operations in the Arkansas River Basin, Colorado (No. Water-Resources Investigations Report 85-4092). Unites States Geological Survey, Lakewood, Colorado.

Payne, J.W., Bettman, J.R., Johnson, E.J., 1992. Behavioral decision research: A constructive processing perspective. American Review of Psychology 43, 87-131.

Reed, P.M., Hadka, D., Herman, J.D., Kasprzyk, J.R., Kollat, J.B., 2013. Evolutionary Multiobjective Optimization in Water Resources: The Past, Present and Future. Advances in Water Resources 51, 438-456.

Roy, B., 1999. Decision-aiding today: What should we expect?, in: Multicriteria Decision Making. Springer, pp. 1-35.

Saaty, T.L., 1980. The Analytic Hierarchy Process: Planning, Priority Setting, Resource Allocation. McGraw-Hill, New York ; London.

Sarewitz, D., Pielke, R.A., 2007. The neglected heart of science policy: reconciling supply of and demand for science. Environmental Science \& Policy 10, 5-16. https://doi.org/10.1016/j.envsci.2006.10.001

Siirtola, H., Räihä, K.-J., 2006. Interacting with parallel coordinates. Interact Comput 18, 1278-1309. https://doi.org/10.1016/j.intcom.2006.03.006

Slovic, P., 1995. The construction of preference. American psychologist 50, 364.

Slovic, P., 1975. Choice between equally valued alternatives. Journal of Experimental Psychology: Human Perception and Performance 1, 280-287.

Smith, R., Kasprzyk, J., Basdekas, L., 2018. Experimenting with water supply planning objectives using the Eldorado Utility Planning Model multireservoir testbed. Journal of Water Resources Planning and Management 144. https://doi.org/10.1061/(ASCE)WR.1943-5452.0000962

Smith, R., Kasprzyk, J., Dilling, L., 2017. Participatory Framework for Assessment and Improvement of Tools (ParFAIT): Increasing the impact and relevance of water management decision support research. Environmental Modelling \& Software 95, 432-446. https://doi.org/10.1016/j.envsoft.2017.05.004

Smits, R., 2002. Innovation studies in the 21st century;: Questions from a user's perspective. Technological Forecasting and Social Change, IPTS S.I. 69, 861-883. https://doi.org/10.1016/S0040-1625(01)00181-0

State of Colorado, 2017. Population Forecasts (2000 - 2050) [WWW Document]. Colorado Demography. URL https://demography.dola.colorado.gov/population/population-totals-colorado-substate/ (accessed 8.4.17).

Thomas, J.J., Cook, K.A., 2006. A visual analytics agenda. IEEE Computer Graphics and Applications 26, 10-13.

Triantaphyllou, E., 2000. Multi-Criteria Decision Making Methods, in: Triantaphyllou, E. (Ed.), MultiCriteria Decision Making Methods: A Comparative Study, Applied Optimization. Springer US, Boston, MA, pp. 5-21. https://doi.org/10.1007/978-1-4757-3157-6_2

Tsoukias, A., 2008. From decision theory to decision aiding methodology. European Journal of Operational Research 187, 138-161.

Tversky, A., 1972. Elimination by aspects: A theory of choice. Psychological Review 79, 281-299.

US EPA, O., 2014. Public Participation Guide: Charrettes [WWW Document]. US EPA. URL https://www.epa.gov/international-cooperation/public-participation-guide-charrettes (accessed 11.18.17). 
Watson, A.A., Kasprzyk, J.R., 2017. Incorporating deeply uncertain factors into the many objective search process. Environmental Modelling \& Software 89, 159-171. https://doi.org/10.1016/j.envsoft.2016.12.001

Woodbury, M., Baldo, M., Yates, D., Kaatz, L., 2012. Joint Front Range Climate Change Vulnerability Study. Water Research Foundation, Colorado.

Woodruff, M.J., Reed, P.M., Simpson, T., 2013. Many Objective Visual Analytics: Rethinking the Design of Complex Engineered Systems. Structural and Multidisciplinary Optimization 48, 201-219.

Wu, W., Dandy, G.C., Maier, H.R., Maheepala, S., Marchi, A., Mirza, F., 2017. Identification of Optimal Water Supply Portfolios for a Major City. Journal of Water Resources Planning and Management 143, 05017007. https://doi.org/10.1061/(ASCE)WR.1943-5452.0000811

Wu, W., Maier, H.R., Dandy, G.C., Leonard, R., Bellette, K., Cuddy, S., Maheepala, S., 2016. Including stakeholder input in formulating and solving real-world optimisation problems: Generic framework and case study. Environmental Modelling \& Software 79, 197-213. https://doi.org/10.1016/j.envsoft.2016.02.012

WUCA, 2015. Embracing Uncertainty: A Case Study Examination of How Climate Change is Shifting Water Utility Planning. Water Utility Climate Alliance, Boulder, CO.

Zagona, E., Fulp, T.J., Shane, R., Magee, Y., Goranflo, H.M., 2001. RiverWare: A generalized tool for complex reservoir system modeling. Journal of the American Water Resources Association 37, 913-929.

Zeff, H.B., Herman, J.D., Reed, P.M., Characklis, G.W., 2016. Cooperative drought adaptation: Integrating infrastructure development, conservation, and water transfers into adaptive policy pathways. Water Resour. Res. 52, 7327-7346. https://doi.org/10.1002/2016WR018771 


\section{Appendix}

This appendix provides technical details about the optimization problem that produced the tradeoffs used in the charrette. For further discussion about the model, the problem formulation, and the tradeoff results that underpin this workshop, refer to Smith et al (2018).

The Eldorado Utility Planning Model was created for this study using in the RiverWare modeling platform (Zagona et al., 2001). RiverWare has features such as built in water rights accounting and a customizable policy language that allowed us to incorporate the level of complexity that is common among real-world Colorado water supply systems. The model has five streamflow input sites in the headwaters of two major subbasins, 11 water users with spatially distributed water storage, diversions, and return flows, and 19 individual water rights ranging from 1888 (most senior) to 1940 (most junior). The hypothetical utility at the center of the optimization problem is surrounded by water users whose more senior rights limit the yields of Eldorado's rights but also offer opportunities to acquire more water. For example, Ag3 is an agricultural user downstream of Eldorado's South Res that has senior rights that can prevent the utility from filling the reservoir, and one of the decision levers allows the utility the utility to purchase a portion of this users water rights. Figure 2 presents the layout of the network and the water rights.

The 13 decision levers, their value ranges, and brief descriptions are presented in Table 3 . The names and order given here match the workshop screenshots in Figures 3 and 4, but are slightly different than how the levers were presented in Smith et al (2018). The workshop names and order were tailored for managers' practical understanding. The different naming schemes are easily translatable between articles. 
Table 3. List of decision levers.

\begin{tabular}{|c|c|c|c|}
\hline Decision Lever & Description & Units & Range \\
\hline Ag3 Purchase & $\begin{array}{l}\text { Percentage of Ag3's senior diversion right to } \\
\text { purchase }\end{array}$ & $\%$ & $0-20$ \\
\hline $\begin{array}{l}\text { Industrial } \\
\text { Purchase }\end{array}$ & $\begin{array}{l}\text { Percentage of Industrial user's mid-seniority } \\
\text { diversion right to purchase }\end{array}$ & $\%$ & $0-20$ \\
\hline $\begin{array}{l}\text { Wholesaler } \\
\text { Shares }\end{array}$ & $\begin{array}{l}\text { Number of additional shares of Wholesaler } \\
\text { water to purchase }\end{array}$ & shares & $0-6,000$ \\
\hline $\begin{array}{l}\text { Ag2 Irr. Co. } \\
\text { Shares }\end{array}$ & $\begin{array}{l}\text { Number of shares of Ag2 Irrigation Co. } \\
\text { water to purchase }\end{array}$ & shares & $0-10,000$ \\
\hline $\begin{array}{l}\text { Interruptible } \\
\text { Shares }\end{array}$ & $\begin{array}{l}\text { Number of shares to include in an } \\
\text { agreement with Ag2 Irrigation Co. for } \\
\text { optional supply leases }\end{array}$ & shares & $0-10,000$ \\
\hline $\begin{array}{l}\text { Conservation } \\
\text { Level }\end{array}$ & $\begin{array}{l}\text { Level of conservation through which to } \\
\text { reduce starting per capita demand; } 0=\text { no } \\
\text { change, } 1=10 \% \text { reduction, } 2=20 \% \\
\text { reduction }\end{array}$ & --- & $0-2$ \\
\hline Dist. Efficiency & $\begin{array}{l}\text { Percentage of distribution efficiency to } \\
\text { pursue by reducing unaccounted-for water } \\
\text { (baseline efficiency is } 90 \% \text { ) }\end{array}$ & $\%$ & $90-93$ \\
\hline $\begin{array}{l}\text { South Res } \\
\text { Volume }\end{array}$ & $\begin{array}{l}\text { Volume by which to expand the South } \\
\text { Reservoir }\end{array}$ & $\begin{array}{l}\mathrm{MCM} \\
(\mathrm{AF})\end{array}$ & $\begin{array}{c}0-2.47 \\
(0-2,000)\end{array}$ \\
\hline $\begin{array}{l}\text { West Slope Res } \\
\text { Volume }\end{array}$ & $\begin{array}{l}\text { Size of a potential new West Slope } \\
\text { Reservoir }\end{array}$ & $\begin{array}{l}\mathrm{MCM} \\
(\mathrm{AF})\end{array}$ & $\begin{array}{c}0-12.3 \\
(0-10,000)\end{array}$ \\
\hline Gravel Pit & $\begin{array}{l}\text { Develop gravel pits to store reusable return } \\
\text { flows downstream of the city; } 0=\text { not } \\
\text { developed, } 1=\text { developed }\end{array}$ & --- & $0-1$ \\
\hline $\begin{array}{l}\text { Exchange to } \\
\text { North Res }\end{array}$ & $\begin{array}{l}\text { Acquire right to exchange reusable return } \\
\text { flows to NorthRes }\end{array}$ & --- & $0-1$ \\
\hline $\begin{array}{l}\text { External Res } \\
\quad \text { Space }\end{array}$ & $\begin{array}{l}\text { Volume of space to rent in an external } \\
\text { reservoir that can facilitate Exchange } \\
\text { efficiency }\end{array}$ & $\begin{array}{l}\mathrm{MCM} \\
(\mathrm{AF})\end{array}$ & $\begin{array}{c}0-3.7 \\
(0-3,000)\end{array}$ \\
\hline $\begin{array}{l}\text { Ag2 Res If \& } \\
\text { When }\end{array}$ & $\begin{array}{l}\text { Pay Ag2 Irrigation Co. to store water in any } \\
\text { available unused space; } 0=\text { off, } 1=\text { on }\end{array}$ & --- & $0-1$ \\
\hline
\end{tabular}

MOEA-assisted optimization evaluates performance based on an objective function vector, $\mathbf{F}(\mathbf{x})$, where $\mathbf{x}$ is the portfolio defined by decision lever values. Each value in the vector results from calculating a separate objective, $f_{\text {objective }}$.

$$
\begin{gathered}
\mathbf{F}(\mathbf{x})=\left(f_{\text {RestLev } 1}, f_{\text {RestLev } 2}, f_{\text {RestLev } 3}, f_{\text {Missedopp }}, f_{\text {NewSupply }}, f_{\text {April1Storage }}, f_{\text {NewStorage }},\right) \\
\forall \mathbf{x} \in \Omega
\end{gathered}
$$


$f_{\text {RestLev } 1}, f_{\text {RestLev } 2}$, and $f_{\text {RestLev } 3}$ are restrictions-based reliability measures ${ }^{5}$. Restriction levels are triggered based on April 1 storage levels, which are used by Front Range, Colorado, utilities to assess their system status for the upcoming year. In the model, restrictions are represented by reductions in outdoor water use (while indoor use is never curtailed). Table 4 summarizes the restriction triggers and impacts.

Table 4. Storage-based triggers and water use impacts of restriction levels.

\begin{tabular}{|c|c|c|c|}
\hline $\begin{array}{c}\text { Current Storage-to-Long Term } \\
\text { Avg Annual Demand }\end{array}$ & Restriction Level & $\begin{array}{c}\text { Resulting Indoor } \\
\text { Use }\end{array}$ & $\begin{array}{c}\text { Resulting } \\
\text { Outdoor Use }\end{array}$ \\
\hline$>=75 \%$ & 0 & $100 \%$ & $100 \%$ \\
\hline$<75 \%$ & 1 & $100 \%$ & $80 \%$ \\
\hline$<50 \%$ & 2 & $100 \%$ & $50 \%$ \\
\hline$<25 \%$ & 3 & $100 \%$ & $0 \%$ \\
\hline
\end{tabular}

where "Current Storage-to-Long Term Avg Annual Demand" is defined as

$$
\text { RestLev }=\frac{\text { Total Water in Storage on April } 1}{\text { Long Term Unrestricted Annual Utility Demand }} \times 100
$$

The three restrictions objectives are calculated as follows:

Minimize the number of years that Eldorado spends in Level 1 Restrictions:

$$
f_{\text {RestLev } 1}(\mathbf{x})=E\left[\sum_{i=1}^{Y} y_{\text {RestLev }_{i}=1}\right]_{t}
$$

Minimize the number of years that Eldorado spends in Level 2 Restrictions:

\footnotetext{
${ }^{5}$ We only showed managers five objectives total during the charrette because limited time with the visualizations precluded showing the full suite of objectives. Objectives minimizing Restrictions Levels 2 and 3 were omitted.
} 


$$
f_{\text {RestLev } 2}(\mathbf{x})=E\left[\sum_{i=1}^{Y} y_{\text {RestLev }_{i}=2}\right]_{t}
$$

Minimize the number of years that Eldorado spends in Level 3 Restrictions:

$$
f_{\text {RestLev } 3}(\mathbf{x})=E\left[\sum_{i=1}^{Y} y_{\text {RestLev }_{i}=3}\right]_{t}
$$

where $Y$ is the number of years simulated per $t$ traces in the hydrologic ensemble. Expectation notation, $E[\quad]$, denotes that the average across the traces was used.

The optimization seeks to minimize the fourth objective, $f_{\text {Missedopp }}$, which measures how efficiently Eldorado uses its supplies and system components to meet demands. It is affected by whether the utility can capitalize on reusable water and also whether Eldorado acquires an overabundance of Wholesaler or Ag2 shares.

$$
\begin{gathered}
f_{\text {Missedopp }}(\mathbf{x})= \\
E\left[\frac{1}{Y} \sum_{i=1}^{Y} \text { (Unused Shares }_{\text {Wholesaler }_{i}}+\text { Unused Shares }_{\text {Interruptible }_{i}}\right. \\
+ \text { Lost Reusable Return Flows } \\
\text { Rle }_{t}
\end{gathered}
$$

Objective five, $f_{\text {NewSupply }}$, is also minimized, and quantifies the amount of "new" water that the utility acquires form shares and other water users or creates through conservation.

$$
\begin{aligned}
& f_{\text {NewSupply }}(\mathbf{x})
\end{aligned}
$$

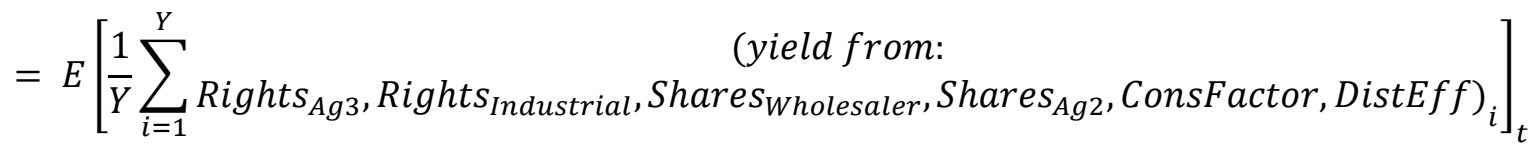


The sixth objective, $f_{\text {April1Storage }}$, seeks to maximize the amount of water Eldorado has in carryover storage on April 1 of every year.

$$
f_{\text {April1Storage }}(\mathbf{x})=E\left[y_{\min }\left(\frac{\text { Total Eldorado April 1 Storage Vol }}{\text { Avg Long Term Annual Demand }}\right) \times 100\right]_{t}
$$

where $y_{\min }$ denotes that the objective is calculated using the minimum annual value over the course of the simulation.

The final objective, $f_{\text {Newstorage }}$, minimizes the total volume of new storage that Eldorado builds.

$$
f_{\text {NewStorage }}(\mathbf{x})=\sum\left[\text { ExpandVol }_{\text {SouthRes }}, \text { BuildVol }_{\text {WestSlopeRes }},(G P * 0.99 \text { MCM })\right]
$$

Note that GP is multiplied by 0.99 million cubic meters (MCM) (800 AF) because the GP lever is on/off or $1 / 0$, but the volume added is $0.99 \mathrm{MCM}(800 \mathrm{AF})$.

The RiverWare model was designed to run for 25 years at a monthly timestep. Portfolios were considered fully implemented at the beginning of the simulation and evaluated over the 25 years. Each simulation took 20 seconds to complete. We embedded the model within the Borg MOEA (Hadka and Reed, 2013) and ran the optimization for approximately 5,000 function evaluations (a separate optimization was run for each hydrologic scenario). The performance of each portfolio was averaged across ten hydrologic traces which were distributed to 10 computing cores using RiverWare's concurrent multiple run management functionality. Each optimization took approximately 36 hours to complete and used the default Borg settings except for the initial population size parameter, which was changed from 100 to 50 so that evolutionary search would commence more quickly (Hadka et al., 2012; Reed et al., 2013). 